\title{
Differential Activation of MAP Kinase Signaling Pathways and Nuclear Factor- $\kappa B$ in Bronchoalveolar Cells of Smokers and Nonsmokers
}

\author{
Keiko Mochida-Nishimura, ${ }^{1,3}$ Krystyna Surewicz, ${ }^{1}$ Janet V. Cross, ${ }^{2}$ Rana Hejal, ${ }^{1}$ Dennis \\ Templeton, ${ }^{2}$ Elizabeth A. Rich, ${ }^{1}$ and Zahra Toossi ${ }^{1}$ \\ ${ }^{1}$ Department of Medicine, Case Western Reserve University, Cleveland, Ohio, USA \\ ${ }^{2}$ Institute of Pathology, Case Western Reserve University, Cleveland, Ohio, USA \\ ${ }^{3}$ Department of Bacterial and Blood Products, National Institute of Infectious Diseases, Tokyo, Japan \\ Accepted November 15, 2000
}

\begin{abstract}
Background: Prolonged exposure of alveolar macrophages (AM) to components of tobacco smoke, including nicotine and aromatic hydrocarbons, may lead to alterations in activation of cellular signaling pathways. In this study, we compared the spontaneous and LPS-stimulated activation of MAP kinases and NF- $\kappa \mathrm{B}$ in bronchoalveolar cells (BAC) from smokers and nonsmokers.

Material and Methods: BAC, which were predominantly comprised of AM, were obtained by bronchoalveolar lavage of healthy volunteering adult smokers and nonsmokers. Nuclear and cytoplasmic extracts were prepared from cell lysates. Activation of NF- $\kappa$ B was assessed by electrophoretic mobility shift assay. Degradation of the inhibitor of NF- $\kappa \mathrm{B}(\mathrm{I} \kappa \mathrm{B})$ and total MAP kinases were assessed by Western blot analysis. Activation of MAP kinases, ERK, SAPK/JNK, and p38 were assessed by immunoprecipitation of cell lysates and kinase assays.
\end{abstract}

Results: LPS induced the activation of NF- $\kappa$ B in a dosedependent manner, but BAC from smokers were approximately 10 times more sensitive, and showed faster kinetics of activation of NF- $\kappa$ B than BAC from nonsmokers. All three classes of MAP kinase-ERK, SAPK, and p38-were simultaneously activated by LPS in BAC from smokers and nonsmokers. However, the individual MAP kinases exhibited differential kinetics of activation. Activation of p38 was more rapid in BAC from smokers, whereas the activation of ERK and SAPK was similar in both groups. Conclusion: The differences in activation of NF- $\kappa \mathrm{B}$ and MAP kinases in BAC from smokers and nonsmokers may relate to the differences in their microenvironment in situ as affected by chronic exposure to cigarette smoke. These differences may contribute to the increased susceptibility of smokers to infections, including infection with HIV-1, and lung disease.

\section{Introduction}

Alveolar macrophages (AM) are continuously exposed to high oxygen tension and inhaled particles. In cigarette smokers, AM additionally are exposed to exogenous stress, such as the components of tobacco smoke, including nicotine and aromatic hydrocarbons. Smoking is known to be a risk factor not only in carcinogenesis but also in opportunistic pulmonary infections, especially in HIV-1-infected patients $(1,2)$. Abnormalities in activation of nuclear factor-kB or stress-activated signal transduction pathways in bronchoalveolar cells (BAC) may underlie the development of infections in the lung. However, little is known about the effect of smoking on signaling pathways in BAC or AM.

Cellular response to extracellular stimuli is controlled via a complex array of phosphorylation

Address correspondence and reprint requests to: Dr. Zahra Toossi, Case Western Reserve University, Division of Infectious Diseases, Biomedical Research Building 10th floor, 10900 Euclid Avenue, Cleveland, OH 44106-4984, USA. E-mail: zxt2@po.cwru.edu cascades $(3,4)$. The mitogen-activated protein (MAP) kinases are an important group of serine/ threonine signaling kinases that play a major role in converting mitogenic and stress stimuli into nuclear responses. In mammalian cells, three major groups of MAP kinases have been identified. The extracellular signal-regulated kinases (ERK1 and ERK2) pathways transmit signals due to mitogenic and differentiation stimuli. The SAPK/JNK and p38 pathways transmit stress signals resulting from oxidative stress or stimulation with inflammatory cytokines, such as tumor necrosis factor alpha (TNF- $\alpha)(4,5)$. Activation of these signal transduction pathways leads to either phosphorylation of transcription factors in the nucleus or translocation of nuclear factors, such as nuclear factor-kappa B (NF- $\kappa$ B), to the nucleus which in turn affect gene expression $(6,7)$.

$\mathrm{NF}-\kappa \mathrm{B}$ exists in the cytoplasm complexed to its inhibitor, $\mathrm{I} \kappa \mathrm{B}-\alpha$. Upon cell stimulation, specific kinases phosphorylate $\mathrm{I} \kappa \mathrm{B}-\alpha$, targeting it for ubiquitin-mediated degradation (8). Common mediators of activation connect the MAP kinase signaling pathway 
and the NF- $\kappa \mathrm{B}$ transcription pathway; for example, both NF- $\kappa$ B and SAPK/JNK are activated through ERK kinase kinase l (MEKKl) (9). However, the involvement of the signaling pathways in activation of $\mathrm{NF}-\kappa \mathrm{B}$ is still controversial (10).

AM from smokers may have an altered activation state and/or responsiveness to stimuli, thus modifying their immune and inflammatory profile. Recent evidence suggests that AM from smokers are activated in situ. For example, higher amounts of reactive oxygen intermediates are released by AM from smokers upon stimulation in vitro (11). Oxygen radical metabolites incite spreading of macrophages through activation of MAP kinase-serum response element signaling pathway (12). In this case, it appears that ERK (p44/42) and p38 MAP kinases, but not SAPK/JNK, are involved. Furthermore, it has been shown that nicotine specifically activates the ERK2 signal transduction pathway in lung cell lines (13). In addition, chronic exposure to nicotine induces T-cell anergy by impairing the ability of $\mathrm{T}$ cells to upregulate inositol triphosphate synthesis in response to ligation of T-cell receptors (14). Further, AM from smokers produce fewer cytokines in response to bacterial lipopolysaccharide (LPS), and smokers have decreased resistance to bacterial infections (15). Previously, our group has shown that AM from smokers are more permissive to HIV-1 infection than AM from nonsmokers (16). Activation of NF- $\kappa$ B appears to be critical to successful infection by HIV-1 (17). However, a systematic comparison of signal transduction pathways, and their relationship to activation of NF$\kappa \mathrm{B}$ in $\mathrm{AM}$ or BAC from smokers and nonsmokers, has not been reported.

In this study, we determined the cellular response of BAC, which are predominantly comprised of AM, from smokers and nonsmokers to LPS by assessment of MAP kinase as well as NF- $\kappa$ B activation cascades. We found that BAC from smokers are more susceptible to activation of NF- $\kappa$ B by LPS than those from nonsmokers, and display an altered pattern of activation of the MAP kinase, p38.

\section{Materials and Methods}

\section{Study Subjects}

Subjects were 18 healthy nonsmokers, 21-39 years of age (range, $28.8 \pm 8.0$ years) and 18 healthy smokers, 23-43 years of age (range, $33.0 \pm 7.3$ ). Smokers were defined as those smoking at least 0.5 pack of cigarettes per day for over 6 months. Nonsmokers were defined as those who had not smoked within the last 1 year or had never smoked. All subjects fulfilled the following criteria: no known risk factors for HIV-1 infection, no medications, no history of heart or lung disease, and no upper respiratory tract infection within 6 months of the study. Informed consent was obtained from each subject. The protocol was approved by the Institutional Review Board for Human Investigation at University Hospitals of Cleveland.
Bronchoalveolar lavage (BAL) and preparation of BAC was performed as described previously (18). Briefly, after anesthetizing the upper airway with topical $4 \%$ lidocaine, a flexible bronchoscope (BF type 4B2 bronchoscope; Olympus, Optical Co, LTD, Lake Success, NY, USA) was wedged into the right middle lobe. Then, $240 \mathrm{ml}$ of $0.9 \%$ sterile saline was instilled into two segments of the middle lobe, and BAL fluid was harvested. BAL fluid was centrifuged at $1500 \mathrm{rpm}, 4^{\circ} \mathrm{C}$ for $10 \mathrm{~min}$. Cell pellets were suspended in Iscove's minimum defined medium (BioWhittaker, Walkersville, MD, USA) containing $10 \%$ pooled human serum, and kept on ice. The mean total yield of BAC in BAL was higher in smokers $\left(65.7 \times 10^{6}\right)$ $(p<.001)$ than in nonsmokers $\left(20.8 \times 10^{6}\right)$. BAC from nonsmokers were $90-95 \%$ nonspecific esterasepositive (AM), 5-10\% lymphocytes, and $<1 \%$ granulocytes as assessed by Wright's stain. BAC from smokers were 94-98\% AM, 2-6\% lymphocytes, and no granulocytes (19). Therefore, BAC from either group was predominantly comprised of AM. Viability as assessed by exclusion of Trypan blue was $>\mathbf{9 5} \%$ in BAC from either group.

\section{Preparation of Cytoplasmic and Nuclear Extracts}

BAC $\left(10^{6}\right.$ cells $)$ were processed either immediately or after incubation in the presence or absence of LPS (Sigma, St. Louis, MO, USA) for 10-120 min in polypropylene tubes under nonadherent conditions. Cytoplasmic and nuclear extracts were prepared as described previously (20). Briefly, BAC were washed with cold PBS, and resuspended in $400 \mu \mathrm{L}$ cold buffer A (10 mM HEPES, pH 7.9; $10 \mathrm{mM} \mathrm{KCl}$; $0.1 \mathrm{mM}$ EDTA; $0.1 \mathrm{mM}$ EGTA; $1 \mathrm{mM}$ DTT; $0.5 \mathrm{mM}$ PMSF; $5 \mu \mathrm{g} / \mathrm{ml}$ trypsin-chymotrypsin inhibitor, antipain, aprotinin, leupeptin; $0.5 \mu \mathrm{g} / \mathrm{ml}$ pepstatin A). The cells were allowed to swell on ice for $15 \mathrm{~min}$, then $25 \mu \mathrm{l}$ of a $10 \%$ solution of NP-40 was added and the tubes were vigorously vortexed for $10 \mathrm{sec}$. The homogenates were centrifuged at $15,000 \times g$ for $30 \mathrm{sec}$. The supernatants (cytoplasmic extracts) were stored at $-20^{\circ} \mathrm{C}$. The nuclear pellets were resuspended in $100 \mu \mathrm{l}$ of ice-cold buffer C (20 mM HEPES, pH 7.9; 0.4 M Nacl; 1 mM EDTA; 1 mM EGTA; 1 mM DTT; $1 \mathrm{mM}$ PMSF; $5 \mu \mathrm{g} / \mathrm{ml}$ trypsin-chymotrypsin inhibitor, antipain, aprotinin, leupeptin; $0.5 \mu \mathrm{g} / \mathrm{ml}$ pepstatin A) and the tubes were vigorously rocked at $4^{\circ} \mathrm{C}$ for $20 \mathrm{~min}$ on a shaking platform. The nuclear extracts were centrifuged at $15,000 \times \mathrm{g}$ for $5 \mathrm{~min}$ at $4^{\circ} \mathrm{C}$ and the supernatants were frozen at $-70^{\circ} \mathrm{C}$. Protein concentration of the extracts was measured by using the protein assay reagent (BioRad, Hercules, CA, USA). The standard curve was obtained using bovine serum albumin (Sigma).

\section{Electrophoretic Mobility Shift Assay}

Oligonucleotide probes used included: NF- $\kappa \mathrm{Bla}$, 5'-CTAGCAAGGGACTTTCCG-CTA-3'; NF- $\kappa$ Blb, 5'-CTAGTAGCGGAAAGTCCCTTG-3' (21). Doublestranded oligonucleotide was prepared by annealing 
the complementary single strands. The probe was radiolabeled with Klenow fragment of DNA polymerase I (Pharmacia LKB, Piscataway, NJ, USA) and $\left[\alpha-{ }^{32} \mathrm{P}\right] \mathrm{dCTP}$ (ICN Pharmaceuticals, Inc., Costa Mesa, CA, USA, specific activity of $3000 \mathrm{Ci} / \mathrm{mmol}$ ). For binding reaction, $1-3 \mu \mathrm{l}$ nuclear extracts $(0.2-0.5$ $\mu \mathrm{g}$ protein) was incubated in $8 \mu \mathrm{l}$ total reaction volume containing $25 \mathrm{mM}$ HEPES, pH 7.9, $5 \mathrm{mM} \mathrm{KCl}$, $0.5 \mathrm{mM}$ EDTA, $1 \mathrm{mg} / \mathrm{ml}$ BSA, $0.25 \mathrm{mM}$ DTT, $10 \%$ v/v glycerol, $0.5 \mu \mathrm{g}$ poly[d(I-C)], and ${ }^{32} \mathrm{P}$-labeled oligonucleotide $(3-10 \mathrm{pg}, 10,000 \mathrm{cpm})$ at $37^{\circ} \mathrm{C}$ for 30 min. For supershift analysis, rabbit antisera against p50, p65, c-Rel, or RelB (kindly provided by Dr. Nancy Rice, NCI-Frederick Cancer Research and Development Center ABL-Basic Research Program) were added 5-10 min prior to the addition of the probe (22). Competition assays were performed in the presence of a 30-fold excess of an unlabeled probe. The reaction products were analyzed by electrophoresis on a $5 \%$ nondenaturing polyacrylamide gel that was pre-electrophoresed for $2-3 \mathrm{hr}$. The gel was dried and analyzed by autoradiography (23).

\section{Western Blot Analysis}

Cytoplasmic extracts containing equal amounts of the protein $(10 \mu \mathrm{g})$ were resolved by discontinuous $12 \%$ SDS-polyacrylamide gel electrophoresis (24). Proteins were transferred onto nitrocellulose membrane (BioRad) in $25 \mathrm{mM}$ Tris, $192 \mathrm{mM}$ glycine, 20\% (v/v) methanol at $100 \mathrm{~V}$ for $1 \mathrm{hr}(25)$. Before blocking, the blot was stained with Panceau $S$ to confirm that equal amounts of protein were transferred to the blot. Transfers were blocked for $2 \mathrm{hr}$ at room temperature with $5 \%$ nonfat milk in Tris-buffered saline containing $0.1 \%$ Tween 20 (TBS-T) and then incubated overnight at $4^{\circ} \mathrm{C}$ with an affinity-purified rabbit polyclonal antibody raised against full length of human I $\kappa$ B- $\alpha$ (\#06-494 Upstate Biotech, Lake Placid, NY, USA). The transfers were washed in TBS-T and incubated for $1 \mathrm{hr}$ at room temperature in HRP-conjugated anti-rabbit IgG secondary antibody (Santa Cruz Biotech, Santa Cruz, CA, USA). The immunoblots were developed with an enhanced chemiluminescence system (ECL; Amersham, Arlington Heights, IL, USA).

\section{Preparation of Cell Lysates and Immunoprecipitation}

Cell lysates of freshly isolated BAC and BAC stimulated for 10 and $30 \mathrm{~min}$ with LPS $(1 \mu \mathrm{g} / \mathrm{ml})$ or sorbitol $(400 \mathrm{mM})$ were prepared using MLB buffer (50 mM MOPS, pH 7.0, $250 \mathrm{mM} \mathrm{NaCl}, 5 \mathrm{mM}$ EDTA, $0.1 \%$ NP40, 1 mM DTT) supplemented with protease inhibitors (1 $\mathrm{mM}$ PMSF, $5 \mu \mathrm{g} / \mathrm{ml}$ aprotinin, $5 \mu \mathrm{g} / \mathrm{ml}$ leupeptin, $10 \mathrm{mM} \mathrm{NaF}, 5 \mathrm{mM}$ Napyrophosphate, $1 \mathrm{mM}$ Na-orthovanadate) and $20 \mathrm{mM}$ beta-glycerophosphate (26). Following lysis $(30 \mathrm{~min}$, $\left.4^{\circ} \mathrm{C}\right)$ the suspension was centrifuged $(15,000 \times \mathrm{g}$, $\left.15 \mathrm{~min}, 4^{\circ} \mathrm{C}\right)$. Protein concentration was determined in supernatants using the BCA protein assay reagent (Pierce, Rockford, IL, USA). Immunoprecipitation reactions were performed using ERK, p38, and SAPK/JNK assay kits (New England Biolabs Inc., Beverly, MA, USA) and following the manufacturer's instructions. Briefly, each sample (500 $\mu \mathrm{g}$ protein) was incubated with immobilized phosphop44/42 MAP kinase (Thr 202/Tyr 204) and with phospho-p38 MAP kinase (Thr180/Tyr 182) monoclonal antibodies. An N-terminal c-Jun (1-89) fusion protein bound to gluthatione-sepharose was used to "pull down" total SAPK/JNKs from cell lysates. All reactions were incubated overnight at $4^{\circ} \mathrm{C}$ with gentle rocking. Immunoprecipitates were collected by centrifugation at $15,000 \times \mathrm{g}$ for $1 \mathrm{~min}$ at $4^{\circ} \mathrm{C}$, washed twice in MLB buffer, and then with the kinase buffer (25 mM Tris pH 7.5, $5 \mathrm{mM}$ beta-glycerophosphate, $2 \mathrm{mM}$ DTT, $0.1 \mathrm{mM} \mathrm{Na}_{3} \mathrm{VO}_{4}, 10 \mathrm{mM} \mathrm{MgCl}{ }_{2}$ ).

\section{In Vitro Kinase Assay}

These assays were performed using commercial kits (New England Biolabs Inc.) following the instructions of the manufacturer. Briefly, the p44/42 (ERK2/1) and p38 MAP kinase assays were carried out by incubating the immunoprecipitates with either ELK-1 or ATF-2 GST fusion protein in the presence of ATP, which allows immunoprecipitated active MAP kinases to phosphorylate substrates. The kinase reaction for SAPK/JNK was performed by incubating c-Jun precipitated SAPK/JNK with ATP. Each reaction was terminated by the addition of SDS sample buffer, and the samples were run on a $12 \%$ SDS-polyacrylamide gel, followed by transfer onto PVDF membrane (Millipore). The membranes were blocked with $5 \%$ nonfat dry milk and incubated overnight at $4^{\circ} \mathrm{C}$ in the presence of primary antibodies. The following primary antibodies were used: phspho-ELK-1 (Ser 383, 1/1000), phosphoATF-2 (Thr 71, 1/1000), and phospho c-Jun (Ser 63, 1/1000). The transfers were washed extensively with TBS-T and incubated for $1 \mathrm{hr}$ at room temperature in horseradish peroxidase-conjugated antirabbit IgG (Santa Cruz Biotech) diluted 1/5000 in TBS-T. The immunoblots were developed with the Super Signal reagent (Pierce, Rockford, IL). Image analysis was performed using Kodak Digital Science ID Image Analysis software.

\section{Statistical Analysis}

The significance of differences between groups was calculated by paired $t$ test.

\section{Results}

Dose-Response and Kinetics of NF- $\kappa B$

Activation in LPS-Stimulated BAC

From Smokers and Nonsmokers

We first assessed whether BAC (which as noted are over $90 \%$ AM) from smokers and nonsmokers were different with regard to activation by LPS. Nuclear extracts were prepared from freshly isolated BAC, or BAC that had been incubated (for $30 \mathrm{~min}$ ) with 


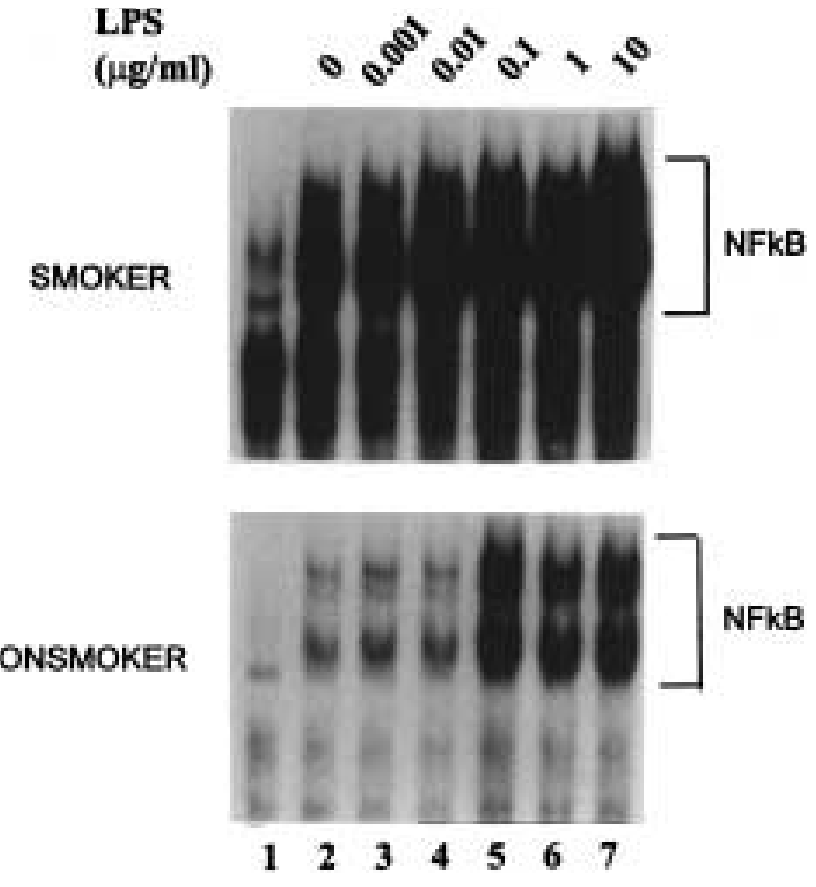

Fig. 1. Dose response of activation of NF- $\kappa B$ in LPSstimulated AM from smokers and nonsmokers. AM were tested immediately after isolation (line 1) or after $30 \mathrm{~min}$ incubation with LPS $0-10 \mu \mathrm{g} / \mathrm{mL}$ (line 2-7). Gel shift assays were then performed. Representative data from one smoker (upper panel) and nonsmoker (lower panel) are shown.

and without varying doses of LPS $(0-10 \mu \mathrm{g} / \mathrm{ml})$ in polypropylene tubes. Then, the binding capacity for $N F-\kappa B$ consensus sequence of nuclear extract was determined (Fig. 1). Some spontaneous activation of NF- $\kappa \mathrm{B}$ was observed in both BAC from smokers and nonsmokers in cultures without LPS. LPS induced the activation of NF- $\kappa$ B in a dosedependent manner in both groups. However, the optimal dose of LPS that activated NF- $\kappa$ B in BAC from smokers and nonsmokers differed; induction of NF- $\kappa$ B occurred at $0.01 \mu \mathrm{g} / \mathrm{ml}$ and $0.1 \mu \mathrm{g} / \mathrm{ml}$ of LPS in BAC from smokers and nonsmokers, respectively. Thus, BAC from smokers were 10 times more sensitive to LPS-induced NF- $\kappa$ B activation than BAC from nonsmokers. Next, using $1 \mu \mathrm{g} / \mathrm{ml}$ LPS, the kinetics of NF- $\kappa$ B activation in BAC from smokers $(n=4)$ and nonsmokers $(n=5)$ was determined. Representative data from one donor from each study group is shown in Figure 2. LPSinduced activation of NF- $\kappa$ B occurred in BAC from smokers at $10 \mathrm{~min}$, peaked at $30 \mathrm{~min}$, and was sustained thereafter. In contrast, LPS-induced activation of NF- $\kappa$ B in BAC from nonsmokers was delayed, becoming evident at $30 \mathrm{~min}$ and peaked at $6 \mathrm{~h}$. Thus, LPS-induced activation of NF- $\kappa$ B in BAC from smokers occurred with faster kinetics than BAC from nonsmokers.

The composition of NF- $\kappa \mathrm{B}$ in unstimulated and LPS-stimulated BAC from smokers and nonsmokers

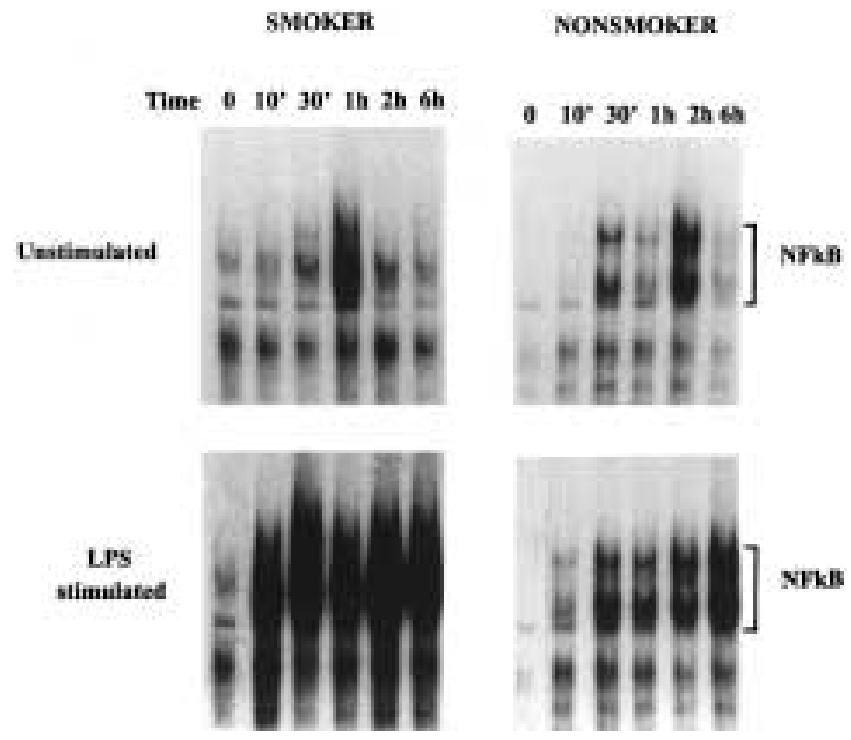

Fig. 2. Kinetics of activation of NF- $\kappa B$ in AM from smokers and nonsmokers. AM were incubated with LPS $(1 \mu \mathrm{g} / \mathrm{mL})$ from $0 \mathrm{~min}$ to $6 \mathrm{hr}$. Gel shift assays were then performed on nuclear extracts. Representative data from one smoker (left panel) and nonsmoker (right panel) are shown.

was also determined. Nuclear extracts were subjected to supershift analysis with antibodies directed at the various NF- $\kappa$ B family members. BAC were cultured with medium or LPS $(1 \mu \mathrm{g} / \mathrm{ml})$ for $30 \mathrm{~min}$. Representative data on BAC from smokers is shown in Figure 3. The composition of NF- $\kappa$ B in both unstimulated and LPS-stimulated BAC was similar, and consisted of p50, p65, and c-Rel, but not relB proteins. All three components (p50, p65, and c-Rel) were significantly higher in LPS-stimulated BAC. As expected, the p65 content was particularly higher in LPS-stimulated samples. However, the composition of NF- $\kappa \mathrm{B}$ in LPS activated and unactivated BAC from smokers was similar to that of BAC from nonsmokers (data not shown).

Basal and LPS-Stimulated Expression of $I \kappa B-\alpha$ in $B A C$

Next, the basal $\left(t_{0}\right)$ and the LPS-stimulated levels of $\mathrm{I} \kappa \mathrm{B}-\alpha$ were compared in BAC from smokers $(n=3)$ and nonsmokers $(n=5)$. Cytoplasmic extracts were prepared from BAC either immediately after BAL $\left(t_{0}\right)$, or after incubation (in polypropylene tubes) with medium or LPS $(1 \mu \mathrm{g} / \mathrm{ml})$ for 10 and $30 \mathrm{~min}$, $1 \mathrm{hr}$, or $6 \mathrm{hr}$. Whereas the basal $\left(t_{0}\right)$ levels of I $\kappa \mathrm{B}-\alpha$ were similar in BAC from smokers and nonsmokers, LPS induced a more rapid degradation of $\mathrm{I} \kappa \mathrm{B}-\alpha$ in BAC from smokers. Representative data from one smoker and one nonsmoker are shown in Figure 4. In LPS-stimulated BAC from smokers, degradation of $\mathrm{I} \kappa \mathrm{B}-\alpha$ occurred as early as $10 \mathrm{~min}$. In contrast, $\mathrm{I} \kappa \mathrm{B}-\alpha$ degradation in BAC from nonsmokers was not detected until $30 \mathrm{~min}$ after LPS stimulation. Thus, 


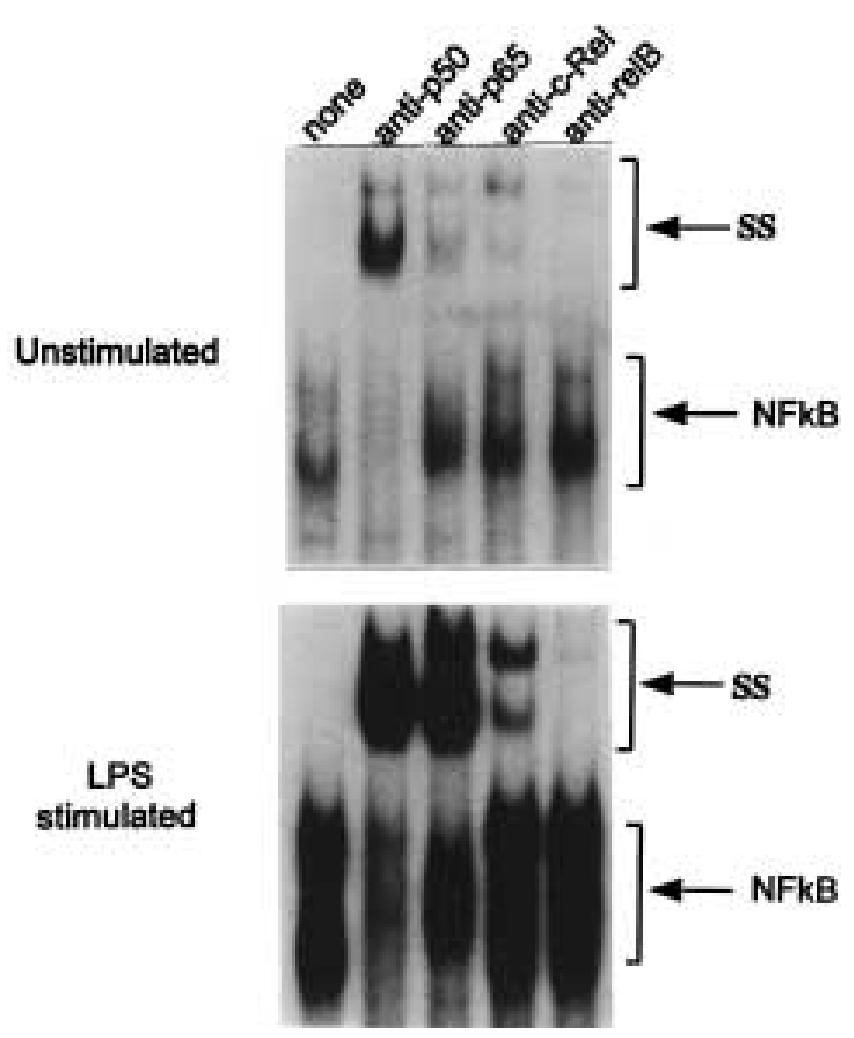

Fig. 3. Composition of NF- $\kappa$ B in AM. AM from smokers and nonsmokers were cultured without (upper panel) and with LPS ( $1 \mathrm{mg} / \mathrm{mL}$ ) (lower panel) for $30 \mathrm{~min}$. Gel shift assays with super shift analysis was then performed using antibodies to p50, p65, c-Rel, and relB. Representative data from one smoker are shown.

the kinetics of $\mathrm{I} \kappa \mathrm{B}-\alpha$ degradation correlated with the activation of NF- $\kappa$ B (Fig. 4) in BAC from smokers and nonsmokers, and was more rapid in smokers.

\section{MAP Kinase Activation}

To determine whether the various MAP kinase "cascades" are differentially activated in BAC from smokers and nonsmokers, the basal and LPSstimulated activation of ERK, SAPK/JNK, and p38 kinases in BAC from smokers and nonsmokers were

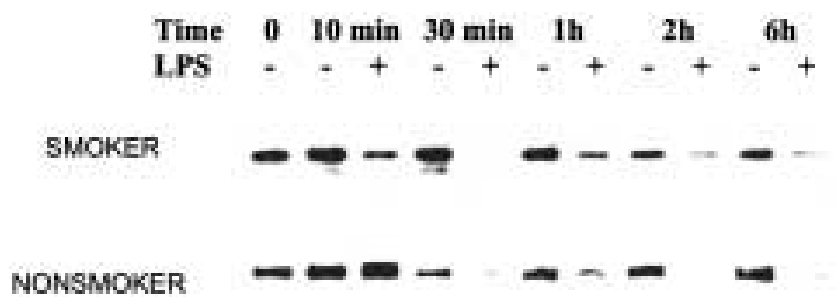

Fig. 4. Degradation of I- $\kappa$ B in AM from smokers and nonsmokers. AM from smokers and nonsmokers were incubated without $(-)$ or with LPS $(1 \mu \mathrm{g} / \mathrm{mL})(+)$ for 0 min to $6 \mathrm{hr}$. Cytoplasmic extracts were assessed for degradation of $\mathrm{I}-\kappa \mathrm{B}$ by Western blot analysis. Representative data from one smoker (upper panel) and one nonsmoker (lower panel) are shown. studied. In preliminary experiments, we compared LPS-induced activation of MAP kinases in BAC to that by sorbitol, which potently induces stress signaling through osmotic shock in cells. LPS-induced $(1 \mu \mathrm{g} / \mathrm{ml})$ activation of MAP kinases was as potent as that by sorbitol $(400 \mathrm{mM})$ at $30 \mathrm{~min}$. This positive control experiment (i.e., BAC stimulated with sorbitol $[400 \mathrm{mM}]$ ) was included in all donors examined.

The kinetics of MAP kinase activation was evaluated in BAC from smokers and nonsmokers that were cultured with LPS $(1 \mu \mathrm{g} / \mathrm{ml})$ for 10 or $30 \mathrm{~min}$, or in the presence of sorbitol $(400 \mathrm{mM})$ for $30 \mathrm{~min}$. Cell lysates were prepared from these cultured cells, and from freshly isolated BAC. Immunoprecipitation of phosphorylated ERK, SAPK/ JNK, and p38 was followed by the assessment of kinase activity by substrate phosphorylation. A representative experiment from each of the two groups (smokers and nonsmokers) for each cascade is shown in Figure 5 ( $\mathrm{A}, \mathrm{B}$, and $\mathrm{C}$, upper panel). The intensity of the bands (measured by densitometry) for activated ERK, SAPK/JNK, and p38 were assessed in each subject and corrected to the basal activity to obtain induction of MAP kinase activity, and mean intensity for activation of each MAP kinase was calculated (Fig. 5, A, B, and $C$, lower panel). The basal levels of activated ERK and SAPK/JNK were similar in the two groups, whereas the basal levels of activated p38 were lower in smokers as compared to nonsmokers $(p<.03)$ (data not shown). After $10 \mathrm{~min}$ of stimulation with LPS, activation of p38, but not ERK or SAPK/JNK, were higher in BAC from smokers as compared to nonsmokers. At $10 \mathrm{~min}, \mathrm{p} 38$ was significantly higher in BAC from smokers as compared to nonsmokers $(p<.045)$, and its activation was maintained at a higher level even at $30 \mathrm{~min}$ (Fig. 5C). ERK was slightly higher in BAC from smokers at $10 \mathrm{~min}$ and plateaued at $30 \mathrm{~min}$, whereas it continued to increase in BAC from nonsmokers (Fig. 5A). In contrast, activation of SAPK/ JNK was similar in BAC from smokers and nonsmokers at $10 \mathrm{~min}$, and was lower in BAC from smokers as compared to BAC from nonsmokers at 30 min (Fig. 5B). However, this difference did not reach statistical significance. Therefore, the kinetics of LPS-induced MAP kinase activation was different in smokers and nonsmokers, and the MAP kinases were differentially activated in BAC from smokers as compared to that from nonsmokers.

To ensure that the differential activation of MAP kinases was not due to differences in amounts of kinases available for phosphorylation in BAC from smokers and nonsmokers, we measured the total basal ERK, p38, and SAPK/JNK by Western blot analysis following LPS stimulation. The total level of unphosphorylated kinases was similar in BAC from smokers $(n=5)$ and nonsmokers $(n=5)$ (Fig. 6). 
A

\section{ERK}

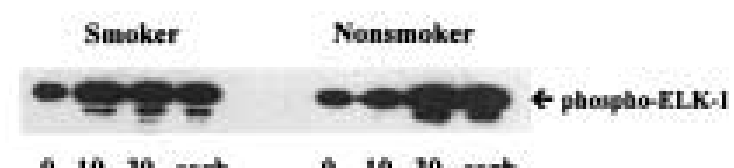

$0 \quad 10 \quad 30$ sarb

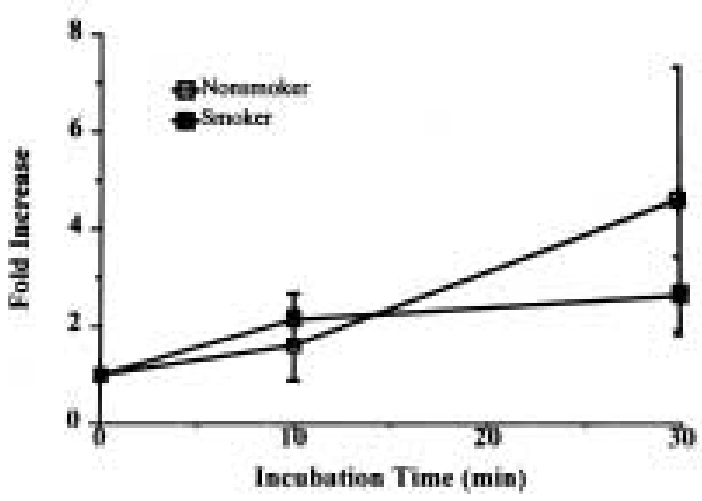

B
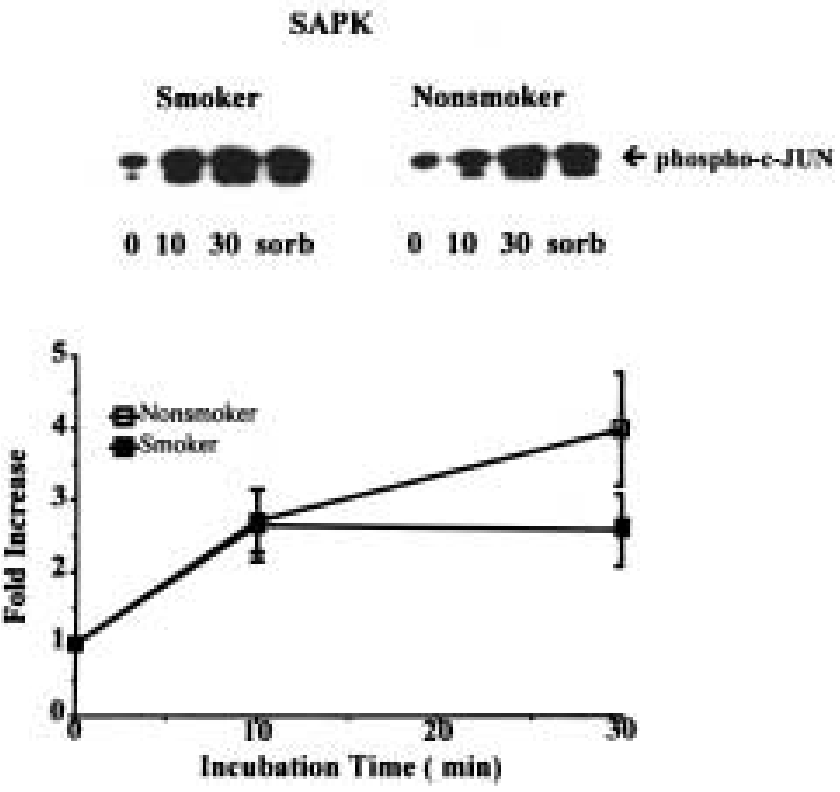

C

P38
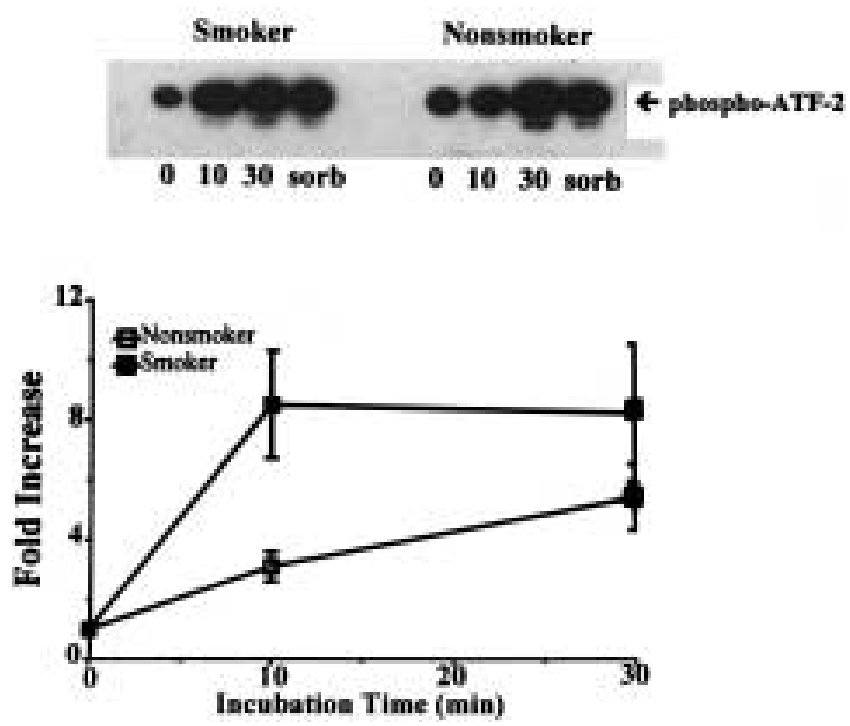

Fig. 5. Activation of MAP kinases in alveolar macrophages from smokers and nonsmokers. AM from smokers and nonsmokers were cultures with LPS $(1 \mu \mathrm{g} / \mathrm{mL})$ from $0-30 \mathrm{~min}$ or with sorbitol $(400 \mathrm{mM})$. Cell extracts were prepared and subjected to immunoprecipitation followed by SDS-PAGE and immunoblotting using monospecific antibodies as in Methods. (A) Activation of ERK. (B) Activation of SAPK. (C) Activation of p38. In A, B, and C, a representative experiment from one smoker and one nonsmoker is shown in the upper panel. In the lower panel, all data from smokers $(n=5)$ and nonsmokers $(n=5)$ were subjected to densitometric analysis. The ratio of MAP kinase activity of LPS stimulated/unstimulated cells was calculated and the mean \pm SEM fold increase in MAP kinase activity, from all donors was subjected to statistical analysis by Student's $t$ test.

\section{Discussion}

Cellular growth and differentiation are dependent on the activation of MAP kinases, which mediate the activation of nuclear factors that induce gene transcription. In this study, we found that BAC from smokers are more sensitive to LPS-induced degradation of $\mathrm{I} \kappa \mathrm{B}-\alpha$ and activation of NF- $\kappa \mathrm{B}$ as compared to BAC from nonsmokers. Interestingly, the pattern of MAP kinase activation was also different in BAC from smokers; of the three MAP kinases, p38 was 
smokers

$\begin{array}{llllll}1 & 2 & 3 & 4 & 5\end{array}$

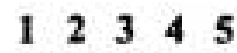

ERK

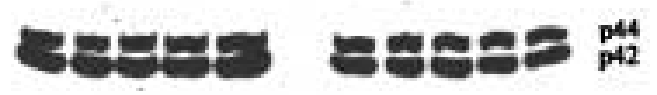

p38
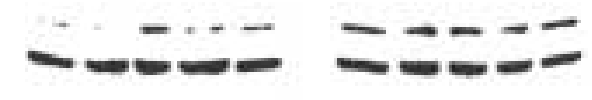

p38

SAPK

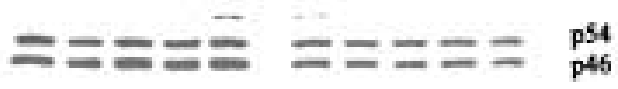

Fig. 6. Total amount of MAP kinases in AM from smokers and nonsmokers. Cell lysates of freshly isolated AM from smokers $(n=5)$ and nonsmokers $(n=5)$ were subjected to Western blot analysis for MAP kinases (ERK, p38, SAPK). Total amount of MAP kinases was similar in AM from smokers and nonsmokers before LPS stimulation.

activated with faster kinetics in BAC from smokers than nonsmokers. Activation of ERK was similar in BAC from both groups, and that of SAPK/JNK appeared to be less sensitive to activation by LPS in BAC from smokers as compared to nonsmokers. These alterations in activation of NF- $\kappa \mathrm{B}$ and MAP kinases may underlie the predisposition of smokers to infection with various pathogens and development of lung disease.

Reactive oxygen intermediates (ROI) activate $\mathrm{NF} \kappa \mathrm{B}$, and the activation of NF- $\kappa \mathrm{B}$ can be abrogated by anti-oxidants (27). Despite controversy, it appears that AM from smokers produce higher levels of ROI than those from nonsmokers (28-33). However, redox-insensitive steps in activation of NF- $\kappa$ B (34) have also been described. For example, Suzuki et al. (6) have suggested that the anti-oxidantinhibitable step of signal transduction required for activation of NF- $\kappa \mathrm{B}$ is located upstream of the redoxinsensitive serine/threonine protein phosphorylation process. Whether in addition to higher production of ROI, lung cells from smokers have alterations in these redox insensitive steps is unknown. Further, it is still unsettled as to whether the level of antioxidants, such as gluthathione reductase (GSH) and superoxide dismutase (SOD), are decreased in BAC from smokers $(31,35,36)$ or increased (37). However, as compared to nonsmokers, smokers have higher GSH concentrations in their epithelial lining fluid (38). In this study, activation of NF- $\kappa \mathrm{B}$ was assessed in BAC from smokers and nonsmokers. BAC, which are $90 \% \mathrm{AM}$, rather than $\mathrm{AM}$ were chosen; any in vitro manipulation of BAC to isolate AM likely would have led to some activation of the cells. We found that BAC from smokers were more susceptible to LPS-induced activation of NF- $\kappa \mathrm{B}$ as compared to BAC from nonsmokers; both lower amounts of LPS and faster kinetics of activation of NF- $\kappa$ B in BAC from smokers support this contention. In further support of these data, the degradation of the cytoplasmic inhibitor of NF- $\kappa \mathrm{B}, \mathrm{I} \kappa \mathrm{B}-\alpha$, was also more rapid in BAC from smokers as compared to nonsmokers. In contrast, the baseline levels of $\mathrm{I} \kappa \mathrm{B}-$ $\alpha$ were similar in smokers and nonsmokers. This latter observation may reflect a degree of activation due to cellular manipulation during the lavage procedure, which could mask any in situ activation in smokers. On the other hand, BAC from smokers may have compensatory mechanisms to neutralize the constant activation of BAC due to continuous exposure to inhaled smoke.

MAP kinases, which are critical to signal transduction from the cell surface to the nucleus, are both differentially regulated $(39,12)$, and display distinct downstream effects $(39,40)$. For example, Ogura et al. have previously shown that the spreading of macrophages induced by oxygen radicals involved activation of ERK and p38, but not SAPK/JNK (12). On the other hand p38 and SAPK/JNK, but not ERK, participate in NO-induced apoptosis in macrophages (41). In this study, the patterns of activation of MAP kinases were different in BAC from smokers and nonsmokers. p38 was induced to higher levels at 10 min in BAC from smokers than from nonsmokers. Both the total MAP kinase available for activation (in basal cells), and sorbitol-induced activation of MAP kinase was similar in BAC from smokers and nonsmokers. Therefore, higher levels of activation in $\mathrm{p} 38$ MAP kinase pathway did not relate to higher amounts of kinases available for phosphorylation. On the other hand, the basal levels of activated p38, but not that of ERK and SAPK/JNK, were significantly lower in BAC from smokers as compared to nonsmokers, which may in part explain its faster kinetics of activation by LPS. p38 has recently been associated with susceptibility to apoptotic cell death (42), and lung cells from smokers are predisposed to apoptosis (43). Whether lower basal levels of activated p38 relate to compensatory inhibitory mechanisms of p38 in BAC from smokers is not known. Further, recently a relationship between activation of p38 with the induction of the pro-inflammatory cytokines IL-12 (39), TNF alpha (44), and IL-8 (44) has been shown. Whether the augmented activation of p38 by bacterial LPS in BAC from smokers underlies an intense inflammatory response upon exposure to microbes which in turn is conducive to predisposition to lung disease is not clear.

On the other hand, BAC from smokers appeared to have a blunted response when LPS-induced activation of SAPK/JNK was compared to BAC from 
nonsmokers; activation in BAC from smokers plateaued after $10 \mathrm{~min}$ and was lower at $30 \mathrm{~min}$ as compared to BAC from nonsmokers. The SAPK/JNK pathway is known to be activated upon in vitro infection by both extracellular (45) and intracellular bacterial pathogens (46). The initial interaction between microbial pathogens, in particular intracellular organisms, and host signaling pathways may be critical to their pathogenesis. Thus the blunted stimulated activation of the SAPK/JNK pathway in smokers may underlie their predisposition to infection with a variety of pathogens. It has been shown that LPS activates all three pathways of MAP kinases in blood monocytes (47), which are the precursors of alveolar macrophages that comprise $90 \%$ of BAC (16). Differences in the activation and cytokine-producing capacity between monocytes and alveolar macrophages, have also been described before $(48,49)$. For example, the transcription factor AP- 1 is induced in monocytes in response to phorbol myristate acetate via the activation of ERK2; however, AP-1 is scarcely induced in alveolar macrophages (50). Whether alterations in activation of MAP kinases, particularly in smokers, is part of the process of recruitment and maturation of monocytes to macrophages in the lung, or due to continuous exposure to oxidative stress or environmental stimuli in situ is not known.

Recent evidence indicates a requirement for MAP kinase signaling in infection of macrophages by HIV-1 (51). Moreover, apparently ERK links cytokine activation of latently HIV-1 infected cells through a cooperative interaction with NF- $\kappa \mathrm{B}$ and other factors (52). Understanding the differential activation of MAP kinases by pathogens in mononuclear phagocytes is important to the application of specific inhibitors of stress-activated pathways (53), as they become available. Whether alterations in responsiveness of MAP kinase pathways in lung macrophages from smokers are conducive to infection by HIV or intracellular pathogens needs to be further elucidated.

\section{Acknowledgments}

This work is dedicated to the memory of Dr. Elizabeth A. Rich. Drs. K. Mochida-Nishimura and K. Surewicz have contributed equally to this work. This study was supported by NIH grant number HL 53247.

\section{References}

1. Drath DB, Davies P, Karnovsky ML, Huber GL. (1979) Tobacco smoke and the pulmonary alveolar macrophages. $A d v$. Exp. Med. Biol. 121: 555-568.

2. Nieman RB, Fleming J, Coker RJ, Harris JRW, Mitchell DM. (1993) The effect of cigarette smoking on the development of AIDS in HIV-1 seropositive individuals. AIDS 7: 705-710.

3. Hunter T, Karin M. (1992) The regulation of transcription by phosphorylation. Cell 70: 375-387.

4. Davis RJ. (1993) The mitogen-activated protein kinase signal transduction pathway. J. Biol. Chem. 268: 14553-14556.
5. Hill CS, Treisman R. (1995) Transcriptional regulation by extracellular signal: mechanisms and specificity. Cell 80: 199-211.

6. Suzuki YJ, Mizuno M, Packer L. (1994) Signal transduction for nuclear factor- $\kappa \mathrm{B}$ activation. J. Immunol. 153: 5008-5015.

7. Karin M. (1999) The beginning of the end: $\mathrm{I} \kappa \mathrm{B}$ kinase (IKK) and NF- $\kappa$ B activation. J. Biol. Chem. 274: 27339-27342.

8. Siebenlist U, Franzoso G, Brown K. (1994) Structure, regulation and function of NF- $\kappa \mathrm{B}$. Annu. Rev. Cell Biol. 10: 405-455.

9. Lee FS, Peters RT, Dang LC, Maniatis T. (1998) MEKK1 activates both $\mathrm{I} \kappa \mathrm{B}$ kinase a and $\mathrm{I} \kappa \mathrm{B}$ kinase b. Proc. Natl. Acad. Sci. USA 95: 9319-9324.

10. Meyer CF, Wang X, Chang C, Templeton D, Tan TH. (1996) Interaction between c-Rel and the mitogen-activated protein kinase kinase kinase 1 signaling cascade in mediating $\kappa \mathrm{B}$ enhancer activation. J. Biol. Chem. 271: 8971-8976.

11. Baughman RP, Corser BC, Strohofer S, Hendricks D. (1986) Spontaneous hydrogen peroxide release from alveolar macrophages of some cigarette smokers. J. Lab. Clin. Med. 107: 233-237.

12. Ogura M, Kitamura M. (1998) Oxidant stress incites spreading of macrophages via extracellular signal-regulated kinase and p38 mitogen-activated protein kinase. J. Immunol. 161: 3569-3574.

13. Heusch WL, Maneckjee R. (1998) Signalling pathways involved in nicotine regulation of apoptosis of human lung cancer cells. Carcinogenesis 19: 551-556.

14. Geng Y, Savage SM, Razanai-Boroujerdi S, Sopori ML. (1996) Effect of nicotine on the immune response. II. Chronic nicotine treatment induces $\mathrm{T}$ cell anergy. J. Immunol. 156: 2384-2390.

15. Almirall J, Bolibar I, Balanzo X, Gonzalez CA. (1999) Risk factors for community-acquired pneumonia in adults: a population-based case-control study. Eur. Respir. J. 13: 349-55.

16. Abbud R, Finegan CK, Guay LA, Rich EA. (1995) Enhanced production of human immunodeficiency virus type 1 by in vitro-infected alveolar macrophages from otherwise healthy cigarette smokers. J. Infect. Dis. 172: 859-63.

17. Swingler S, Morria A, Easton A. (1994) Tumour necrosis factor alpha and interleukin- 1 beta induce specific subunits of NF- $\kappa$ B to bind the HIV-1 enhancer: characterisation of transcription factors controlling human immunodeficiency virus type 1 gene expression in neural cell. Biochem. Biophys. Res. Commun. 203: 623-30.

18. Hirsch CJ, Ellner JJ, Rusell DG, Rich EA. (1994) Complement receptor mediated uptake and tumor necrosis-a mediated growth inhibition of Mycobacterium tuberculosis by human alveolar macrophages. J. Immunol. 152: 743-753.

19. Li CY, Lam KW, Yam LT. (1973) Esterases in human leukocytes. J. Histochem. Cytochem. 21 : 1-4.

20. Schreiber E, Matthias P, Muller MM, Schaffner W. (1989) Rapid detection of octamer binding protein with 'miniextracts' prepared from a small number of cells. Nucleic Acid Res. 17: 6419.

21. Berkhout B, Kuan-Ten J. (1992) Functional roles for the TATA promoter and enhancers in basal and Tat-induced expression of the human immunodeficiency virus type 1 long terminal repeat. J. Virol. 66: 139-149.

22. Cross JV, Deak JC, Rich EA, Mochida K, Templeton DJ. (1999) Quinone reductase inhibitors block SAPK/JNK and NF- $\kappa$ B pathways and potentiate apoptosis. J. Biol. Chem. 44: 31150-31154.

23. Xu YL, Adya N, Siores E, Gao Q, Giam CZ. (1990) Cellular factors involved in transcription and Tax-mediated transactivation directed by the TGACGT motifs in human T-cell leukemia virus type 1 promotor. J. Biol. Chem. 33: 2028520292.

24. Laemmli UK. (1970) Cleavage of structural proteins during the assembly of the head of bacteriophage T4. Nature 227: 680-686.

25. Towbin H, Staehelin T, Gordon J. (1979) Electrophoretic transfer of proteins from polyacrylamide gels to nitrocellulose sheets: Procedure and some applications. Proc. Natl. Acad. Sci. USA 76: 4350-4353. 
26. Deak JC, Cross JV, Lewis M, Qian Y, Distelhorst CW, Templeton DJ. (1998) FAS-induced proteolytic activation and intracellular redistribution of the stress-signaling kinase MEKK 1. Proc. Natl. Acad. Sci. USA 95: 5595-5600.

27. Schreck R, Rieber P, Baeuerle PA. (1991) Reactive oxygen intermediates as apparently widely used messengers in the activation of the NF- $\kappa$ B transcription factor and HIV-1. EMBO J. 10: $2247-2258$.

28. Krejsa CM, Nadler SG, Esselstyn JM, Kavanagh TJ, Ledbetter JA, Schieven GL. (1997) Role of oxidative stress in the action of vanadium phosphotyrosine phosphatase inhibitors. J. Biol. Chem. 272: 11541-11549.

29. Hoidal JR, Niewoehner DE. (1982) Lung phagocytes recruitment and metabolic alterations induced by cigarette smoking in human and hamsters. Am. Rev. Respir. Dis. 126: 548-552.

30. Martin RR. (1973) Altered morphology and increased acid hydrolase content of pulmonary macrophages from cigarette smokers. Am. Rev. Respir. Dis. 107: 596-601.

31. Hubbard RC. (1987) Oxidants spontaneously released by alveolar macrophages of cigarette smokers can inactivate the active site of alpha 1-antitrypsin, rendering it ineffective as an inhibitor of neutrophil elastase. J. Clin. Invest. 80: 12891295.

32. Kondo T, Tagami S, Yoshioka A, Nishimura M, Kawakami Y. (1994) Current smoking of elderly men reduces antioxidants in alveolar macrophages. Am. J. Respir. Crit. Care Med. 149: 178182.

33. Skold CM, Lundahl J, Hallden G, Hallgren M, Eklund A. (1996) Chronic smoke exposure alters the phenotype pattern and the metabolic response in human alveolar macrophages. Clin. Exp. Immunol. 106: 108-113.

34. Thomassen MJ, Barna BP, Wiedemann HP, Farmer M, Ahmad M. (1988) Human alveolar macrophages function: differences between smokers and nonsmokers. J. Leukoc. Biol. 44: 313318.

35. Teramoto S, Uejima Y, Teramoto K, Ouchi Y, Fukuchi Y. (1996) Effect of age on alteration of glutathione metabolism following chronic cigarette smoke inhalation in mice. Lung 174: 119-126.

36. DiSilvestro RA, Pacht E, Davis B, Jarjour N, Joung H, TrelaFulop K. (1998) BAL fluid contains detectable superoxide dismutase 1 activity. Chest 113: 401-404.

37. Hilbert J, Mohsenin V. (1996) Adaptation of lung antioxidants to cigarette smoking in humans. Chest 110: 916-920.

38. Melloni B, Lefebvre MA, Bonnaud F, Vergnenegre A, Grossin L, Rigaug M, Cantin A. (1996) Antioxidant activity in bronchoalveolar lavage fluid from patients with lung cancer. Am. J. Respir. Crit. Care Med. 154: 1706-1711.

39. Wurzel H, Yeh CC, Gairola C, Chow CK. (1995) Oxidative damage and antioxidant status in the lungs and bronchoalveolar lavage fluid of rats exposed chronically to cigarette smoke. J. Biochem. Toxicol. 10: 11-17.

40. Feng GJ, Goodridge HS, Harnett MM, Wei XQ, Nikolaev AV, Higson AP, Liew FY. (1999) Extracellular signal-related kinase (ERK) and p38 mitogen-activated protein (MAP) kinases differentially regulate the lipopolysaccharide-mediated induction of inducible nitric oxide synthase and IL-12 in macrophages: Leishmania phosphoglycans subvert macrophage
IL-12 production by targeting ERK MAP kinase. J. Immunol. 163: 6403-6412.

41. Matthews JS, O'Neill LAJ. (1999) Distinct roles for $\mathrm{p} 42 / \mathrm{p} 44$ and p38 mitogen-activated protein kinases in the induction of IL-2 by IL-1. Cytokine 9: 643-655.

42. Jun CD, Oh CD, Kwak HJ, et al. (1999) Overexpression of protein kinase C isoforms protects RAW 264.7 macrophages from nitric oxide-induced apoptosis: involvement of c-Jun Nterminal kinase/stress-activated protein kinase, p38 kinase, and CPP-32 protease pathways. J. Immunol. 162: 3395-3401.

43. Shrifin VI, Anderson P. (1999) Trichothecene mycotoxins trigger a ribotoxic stress response that activates c-Jun $\mathrm{N}$ terminal kinase and p38 mitogen-activated protein kinase and induces apoptosis. J. Biol. Chem. 274: 13985-13992.

44. Bingisser R, Stey C, Weller M, Groscurth P, Russi E, Frei K. (1996) Apoptosis in human alveolar macrophages is induced by endotoxin and is modulated by cytokines. Am. J. Respir. Cell Mol. Biol. 1: 64-70.

45. Arbabi S, Garcia I, Bauer GJ, Maier RV. (1999) Alcohol (ethanol), inhibits IL-8 and TNF: role of the p38 pathway. J. Immunol. 162: 7441-7445.

46. Kitchens R. (2000) Role of CDI4 in cellular recognition of bacterial lipopolysaccharides. Chem. Immunol. 74: 61-82.

47. Procyk KJ, Kovarik P, von Gabain A, Baccarini M. (1998) Salmonella typhimurium and lipopolysaccharide stimulate extracellularly kinase activation in macrophages by a mechanism involving phosphatidylinositol 3-kinase and phospholipase D as novel intermediates. Infect. Immun. 67: 1011-1017.

48. Scherle PA, Jones EA, Favata MF, et al. (1998) Inhibition of MAP kinase kinase prevents cytokine and prostoglandin E2 production in lipopolysaccharide stimulated monocytes. J. Immunol. 161: 5681-5686.

49. Monick MM, Carter BA, Gudmundsson G, Geist LJ, Hunninghake GW. (1998) Changes in PKC isoforms in human alveolar macrophages compared with blood monocytes. Am. J. Physiol. 275: L389-397.

50. Toossi Z, Hirsch CS, Hamilton BD, Knuth CK, Friedlander MA, Rich EA. (1996) Decreased production of TGF-beta 1 by human alveolar macrophages compared with blood monocytes. Immunology 156: 3461-3468.

51. Biggs TE, Cooke SJ, Barton CH, Harris MP, Saksela K, Mann DA. (1999) Induction of activator protein 1 (AP-1) in macrophages by human immunodeficiency virus type-1 NEF is a cell-type-specific response that requires both hck and MAPK signaling events. Mol. Biol. 290: 21-35.

52. Yan X, Chen Y, Gabuzda D. (1999) ERK MAP kinase links cytokine signals to activation of latent HIV-1 infection by stimulating a cooperative interaction of AP-1 and NF-kappaB. J. Biol. Chem. 274: 27981-27988.

53. Popik W, Hesselgesser JE, Pitha PM. (1998) Binding of human immunodeficiency virus typel to CD4 and CXCR4 receptor differentially regulates expression of inflammatory genes and activates the MEK/ERK signaling pathway. J. Virol. 72: 6406-6413.

54. Sebolt-Leopold JS, Dudley DT, Herrera R, et al. (1999) Blockade of the MAP kinase pathway suppresses growth of colon tumors in vivo. Nat. Med. 5: 810-816. 